\title{
Propaganda e crítica social nas cronologias dos almanaques astrológicos durante a Guerra Civil inglesa no século XVII
}

Propaganda and social criticism in the chronologies of the astrological almanacs during the English Civil War in $17^{\text {th }}$ century

Juliana Mesquita Hidalgo Ferreira*

\section{RESUMO}

Este artigo é parte de uma ampla investigação sobre a utilização dos almanaques astrológicos durante a Guerra Civil inglesa no século XVII como veículo de propaganda e crítica social. Durante esse conflito, havia astrólogos partidários das forças parlamentaristas, como John Booker, e outros partidários das forças realistas, como George Wharton. O presente trabalho analisa algumas dessas publicações, mostrando como o envolvimento político dos autores se manifestava de forma explícita (e, algumas vezes, não tão direta) nos referidos almanaques.

Palavras-chave: astrologia; propaganda; Guerra Civil inglesa.

\section{ABSTRACT}

This article is part of an extensive investigation carried out concerning the use of astrological almanacs during the English Civil War in the $17^{\text {th }}$ century as a medium for propaganda and social criticism. During that conflict there were astrologers who were partisans of the Parliament, such as John Booker, and other who supported the King, such as George Wharton. This work analyses some of those publications, showing that the political commitment of the authors was noticeable in an explicit form (and sometimes in an indirect way) in those almanacs.

Keywords: astrology; propaganda; English Civil War.

\footnotetext{
* Pontifícia Universidade Católica de São Paulo; Fapesp. Rua Dona Ana de Barros, 173. 02423-020 São Paulo - SP - Brasil. juliana_hidalgo@yahoo.com.
} 


\section{A ASTROLOGIA INGLESA NA ÉPOCA}

$\mathrm{Na}$ Inglaterra da década de 1640 a astrologia florescia. A existência de influência dos astros fazia parte do imaginário das pessoas de modo geral. Costumava, aliás, ser aceita pelos que criticavam a possibilidade de estudar essas influências e prever seus efeitos, especialmente no que dizia respeito a eventos humanos.

Pode-se dizer que o cenário das críticas a que a astrologia estava sujeita se mantinha praticamente estático desde os seus primórdios. Os ataques à astrologia pareciam incapazes de abalar a sua credibilidade perante a população, que costumava se dirigir aos consultórios dos astrólogos em busca de prognósticos individuais específicos.

Esses profissionais eram procurados por pessoas de todas as camadas sociais em busca de respostas para as mais variadas questões: prognósticos sobre relacionamentos amorosos, saúde, recuperação de bens roubados, jogos, indicações de dias astrologicamente mais favoráveis para casar, viajar, realizar negócios etc. Recebiam também clientes interessados em tratamentos médicos elaborados e ministrados de acordo com influências astrológicas.

$\mathrm{O}$ atendimento nos consultórios era impulsionado pela publicação dos almanaques astrológicos; atividade pela qual o profissional recebia muito pouco, mas que servia justamente como propaganda de seus serviços particulares. ${ }^{1}$

Os almanaques astrológicos fizeram enorme sucesso especialmente a partir de meados do século XVII. Eram publicações anuais, de grande importância prática para a vida das pessoas, extremamente baratas e disponíveis para consulta até mesmo nas barbearias.

Traziam um calendário mês a mês, com os dias santos e festas religiosas, a duração do dia e da noite e as fases da lua (informações essenciais por não haver energia elétrica na época), os aspectos astrológicos e as previsões meteorológicas com base nessas configurações. Apresentavam comentários sobre as estações do ano e eclipses esperados, além de uma série de outras informações úteis como listas de feiras e estradas, tabelas de juros, datas de funcionamento de tribunais, cronologias históricas, recomendações médicas, sugestões relacionadas à agricultura, à jardinagem etc.

\section{A Guerra Civil e a ASTROlogia}

Logo no início do século XVII, Francis Bacon, um dos filósofos ingleses mais influentes, acenou com a possibilidade de prever eventos relacionados a grandes massas populacionais, incluindo eventos de caráter político e religio- 
so. Para ele, a previsibilidade das guerras era comparável à previsibilidade das inundações. Eram ocorrências naturais, que permitiam prognósticos igualmente legítimos. ${ }^{2}$

Durante a Guerra Civil, a capacidade efetiva de motivação das previsões políticas foi explorada. A astrologia serviu como "propaganda de guerra" a ambos os lados do conflito. As previsões sobre o desenrolar dos combates eram aceitas pela maior parte dos pobres soldados que se amontoavam nos campos de batalha. Promessas de vitória eram o encorajamento de que muitos precisavam, e alguns astrólogos, cientes disso, fizeram uso de seus escritos como instrumentos de persuasão.

O ritmo daquela "batalha de publicações" foi frenético, e pareceu coincidir com o próprio ritmo intenso dos combates. Nos seus almanaques anuais e outras obras publicadas incessantemente, astrólogos como George Wharton, William Lilly e John Booker apresentaram prognósticos sobre questões políticas, sociais e religiosas. Os astrólogos, estivessem eles a favor do rei Charles I ou do Parlamento, tinham consciência do poder da "arma de propaganda" em suas mãos. ${ }^{3}$

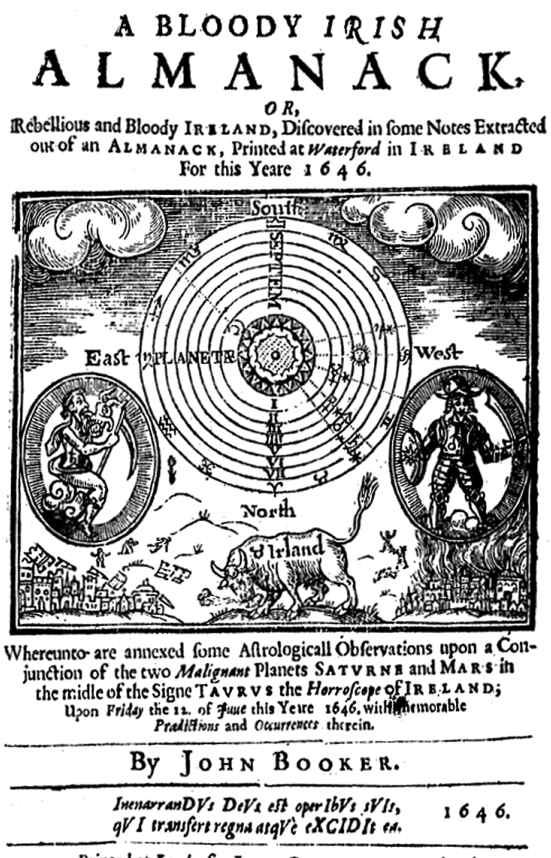

Printed at Londonfor JOHN PARTRIDGE, 1646.

Figura 1 - Folha de rosto de um almanaque publicado pelo astrólogo John Booker em 1646. 
Muitas vezes indo bem além da especificidade que as regras astrológicas permitiam, as previsões apontavam datas e locais em que um lado ou outro seria vitorioso e refletiam bastante diretamente o engajamento desses profissionais no conflito. Outras vezes, como se pode notar, esses astrólogos simplesmente deixavam de lado a astrologia e expunham suas apreciações pessoais sobre a realidade que os cercava. Tanto suas previsões astrológicas, quanto suas opiniões sem embasamento astrológico tinham grande credibilidade perante o público.

Não é exagero dizer que esses profissionais eram, na época, formadores de opinião. E isso era fundamental, já que ambas as forças envolvidas no conflito necessitavam do empenho dos soldados, bem como do apoio da população para a instalação e manutenção das tropas nos condados. Eram importantes, para isso, uma eficiente propaganda e estratégias de convencimento, pois, como se sabe, a população de modo geral desejava paz, resistia a participar do conflito e tratava as tropas com hostilidade, chegando, em alguns casos extremos, a expulsá-las de seus territórios. A guerra, de fato, representava transtorno. Trazia a violência para muito perto, pois além dos combates, os soldados mal pagos cometiam pilhagens. Além disso, impingia taxações ainda mais pesadas e muitas vezes provocava a perda dos meios de subsistência. O teor das previsões era, portanto, fundamental, já que as derrotas faziam diminuir ainda mais o apoio, pois pareciam tornar inúteis os pesados esforços e encargos necessários para mantê-lo. ${ }^{4}$

\section{OS ALMANAQUES ASTROLÓGICOS DA DÉCADA DE 1640}

A pesquisa que deu origem a este artigo analisou vasta gama de almanaques astrológicos ingleses da década de 1640, e pôde identificar vários pontos relevantes. À exceção de poucos trabalhos analisados, a maior parte não apresenta comentários explícitos nem mesmo mensagens implícitas ou propositadamente codificadas acerca de questões políticas, religiosas e sociais da época.

Em boa parte do material analisado nada foi encontrado (mesmo em seções de aparência inocente como listas de feiras etc.) que pudesse sugerir a intenção dos autores de expressar opiniões acerca dessas questões ou mesmo qualquer iniciativa de sensibilizar o leitor para esses assuntos. Isso pode ser dito também a respeito dos almanaques publicados após a eclosão da Guerra Civil em 1642, quando a censura caiu e os autores tiveram mais liberdade de expressão. ${ }^{5}$ 
A simples leitura desses almanaques não demonstra que foram escritos num período tão conturbado da história inglesa. De modo geral, nota-se, aliás, certa apatia quando se compara os almanaques de um mesmo autor para anos consecutivos. Havia pouca ou nenhuma mudança de um ano para o outro no que diz respeito ao conteúdo dos almanaques.

Mesmo os comentários sobre as quatro estações muitas vezes eram apenas descrições gerais das suas qualidades, sem qualquer previsão específica para o ano em questão. Em relação aos eclipses esperados para o ano, os comentários geralmente se restringiam a uma breve descrição do evento desacompanhada de prognósticos astrológicos mesmo no que diz respeito à meteorologia.

A grande maioria dos autores parecia tratar com indiferença as delicadas questões que então faziam parte do cotidiano dos seus leitores. Porém, alguns poucos astrólogos, pode-se notar, expuseram em seus almanaques previsões astrológicas sobre a situação política, religiosa e social, além de suas próprias reflexões acerca desses assuntos.

Pelo que se pôde notar, isso ocorreu de forma mais clara à medida que a situação social se agravou, nos trabalhos de autores como John Booker e George Wharton, nas seções já comuns aos almanaques da época. E, como se pode observar, os que se dispuseram a tecer comentários políticos pareceram de fato aderir abertamente à posição escolhida.

Os almanaques do astrólogo George Wharton são um bom exemplo disso. As edições para os anos de 1641 e 1642, escritas antes da eclosão da guerra, apresentam cálculos para a cidade de Durham e foram publicadas pela Company of Stationers. Já a edição para o ano de 1644 traz suas previsões calculadas para a cidade de Oxford, principal reduto realista durante a guerra, e na folha de rosto mostra a seguinte inscrição: "Impresso em Oxford por ordem de Sua Majestade".6

O almanaque de 1642 de Wharton já insinuava sua posição de apoio ao rei. Apresentava uma tabela de reis ingleses, comum aos almanaques daquela década, mas terminava com um aconselhamento nada habitual para que as pessoas não amaldiçoassem o rei nem mesmo em pensamento. Já na edição de 1644 , a tabela e o comentário parecem ter ganhado mais destaque ao serem inseridos ainda na abertura da publicação.

É interessante notar ainda que as edições para 1641 e 1642 apresentavam no início dos calendários pequenos poemas com mensagens codificadas em algumas de suas linhas. Essas mensagens traziam comentários sobre as circunstâncias políticas, sociais e religiosas da época, e em alguns casos, insinua- 
vam o apoio de Wharton ao rei. Já na edição de 1644 tais poemas cifrados não aparecem, mas o calendário carrega consigo uma interessante cronologia para a Guerra Civil, escrita em linguagem totalmente clara e notadamente propagandista da causa realista.

À medida que a situação se complicava, Wharton parecia se empenhar de modo mais intenso e explícito na defesa de suas convicções. Isso se pode notar até mesmo se compararmos as folhas de rosto de edições sucessivas de seus almanaques. Os exemplares para 1641 e 1642 davam destaque ao que era comum na época: previsões meteorológicas e comentários sobre as estações do ano. Já na folha de rosto do almanaque para 1644 não havia alusão a esses elementos que, até então, tanto pareciam chamar a atenção das pessoas e tornavam o almanaque atrativo. $\mathrm{O}$ destaque impresso na folha de rosto era para "uma breve Cronologia das mais notáveis ocorrências desde o começo desta Rebelião”.

Aliás, de fato, pouco espaço nesse almanaque é dedicado às previsões meteorológicas. E embora houvesse algumas seções genéricas, comuns aos almanaques da década de 1640 (como instruções sobre sangrias, comentários sobre doenças, as estações do ano etc.), os comentários sobre política e a guerra civil foram a tônica do almanaque de Wharton para aquele ano.

Apontamentos sobre a guerra, de fato, eram de grande interesse para os leitores dos almanaques, como evidencia o teor das inscrições existentes em exemplares dessas publicações ainda hoje conservados.

Sabe-se que os almanaques eram utilizados pelas pessoas como uma espécie de agenda. Os compromissos diários eram anotados em lacunas deixadas em branco pelo autor, especialmente para esse fim, ao lado de cada mês do calendário. Um exemplar do almanaque de John Booker para 1643, conservado na British Library, mostra, por exemplo, que seu proprietário se interessava pela guerra a ponto de anotar nessas lacunas os principais acontecimentos de cada mês do conflito. Deve-se destacar, aliás, que não devia ser meramente casual a escolha de um almanaque de Booker para realizar tais anotações, já que o astrólogo foi, na época, um dos que mais utilizaram seus escritos para tratar de assuntos relativos às disputas então em curso.

\section{AS CRONOLOGIAS}

Uma seção bastante freqüente na grande maioria dos almanaques é a cronologia histórica, muitas vezes anunciada como "a cronologia dos eventos 
importantes para a história da humanidade desde o início do mundo". $\mathrm{Cu}$ riosamente, no entanto, nos almanaques da década de 1640, essas cronologias raramente chegam até próximo ao ano das publicações. Muitas apresentam como último registro algo ocorrido oito ou nove anos antes, às vezes até mais. Essas cronologias, portanto, não fazem referência aos episódios então recentes, muito menos aos acontecimentos relacionados à Guerra Civil.

É interessante pontuar, aliás, que geralmente os anos se passavam e novos eventos não eram incluídos nessas cronologias. Essa constatação é possível quando não se analisam os almanaques de forma isolada. Neste caso, ao contrário, são comparadas as produções de um mesmo autor para anos consecutivos a fim de verificar possíveis mudanças de comportamento, como a inclusão ou exclusão de seções, a inexistência de comentários sobre as condições da sociedade em determinado ano e a existência desses comentários no ano seguinte.

Esse procedimento, no caso das cronologias, revela outras situações potencialmente significativas. Nota-se que o almanaque Dove de 1641, por exemplo, registrou, em tom animado, a expedição do rei Charles I à Escócia, em 1639, para "calar os escoceses". O resultado desastroso da empreitada pode estar relacionado ao fato de, nos anos seguintes, o mesmo almanaque excluir esse registro da cronologia. ${ }^{7}$

Outro ponto que não se poderia deixar de destacar é a importância do modo como os registros aparecem na cronologia. Um caso bastante interessante diz respeito ao registro de um episódio notório na história inglesa. Em novembro de 1605, papistas tentaram, sem sucesso, matar o rei e os membros da Câmara dos Lordes e dos Comuns, colocando grande quantidade de explosivos debaixo do Parlamento na ocasião de uma visita real.

O modo como esse acontecimento é mencionado nas cronologias varia de maneira bastante peculiar de um almanaque para outro. E, nesse caso, é bem possível que as diferentes nuances dadas às descrições desse evento sejam reflexo do engajamento religioso e da opinião pessoal de cada autor a respeito daquela ocorrência.

Nessas cronologias, há registros tão eloqüentes no que diz respeito à indignação em relação a esse acontecimento quanto "o condenável powder treason", no almanaque de Poole para 1642, ou "a diabólica tentativa do Powder treason", na edição de Pond para 1643. O mais comum, no entanto, é encontrarmos “The Powder-treason" ou "Gunpowder Treason", tal como nos almanaques de Swallow, Wing, Dove e White para 1641. Sobre estes últimos registros em particular, deve-se notar que o uso da palavra treason já traz consigo 
embutido a reprovação à tentativa do grupo católico. Vale destacar, ainda, que outros detalhes de boa parte dessas cronologias sugerem que seus autores eram protestantes convictos ou ao menos tinham a intenção de defender grupos religiosos protestantes. É bastante significativo, por exemplo, que, numa cronologia que reúne poucos eventos, Swallow parece fazer questão de registrar: "Martinho Lutero pela primeira vez se opôs ao Papa" e "O massacre de Protestantes na França”. Igualmente emblemático é o fato de que, também em curtas cronologias, Wing e White registram esse último episódio simplesmente como "massacre na França”. Aliás, se o próprio fato de a morte dos protestantes ser registrada como "massacre" já indica por si só reprovação à ocorrência, mais contundente ainda é o modo como Dove se refere ao episódio: "O massacre de Protestantes em um casamento na França. Onde não houve tanto vinho bebido quanto sangue derramado...."

Como se pode notar por esses exemplos, as cronologias dos almanaques astrológicos revelam muito a respeito das atitudes dos seus autores em relação à realidade que os cercava. Nesse sentido, o presente artigo se dedica a analisar alguns aspectos de cronologias particularmente interessantes observadas na leitura dos almanaques da década de 1640: a cronologia satírica apresentada pelo The Welsh-Mans new Almanack em 1643, e a cronologia da guerra publicada por Wharton no seu almanaque para 1644. E, no caso desta última, discutiremos também a correspondente resposta apresentada pelo astrólogo rival John Booker em seu almanaque.

\section{A Cronologia do The Welsh-Mans new Almanack de 1643}

Dentre os almanaques especialmente interessantes da década de 1640 e, ao mesmo tempo, particularmente difíceis de serem compreendidos podem ser destacados os almanaques satíricos. Em meio a frases propositadamente sem o menor sentido, zombarias sobre eventos ocorridos na época e personagens conhecidos pelo público leitor, esses trabalhos constituem muitas vezes um material rico em termos de crítica social.

O The Welsh-Mans new Almanack de 1643, escrito, pelo que se pode notar, numa linguagem intencionalmente repleta de erros, apresenta uma cronologia de eventos notáveis no "Principado de Gales e também no Condado da Inglaterra".

Embora, como dissemos, uma seção dedicada à cronologia fosse comum 
nos almanaques, nada se compara à irreverente cronologia apresentada nessa publicação burlesca. Boa parte dos eventos mencionados como históricos são do tipo: "Desde que ele [assim o autor do almanaque refere-se a si próprio] comprou duas jardas de pudim por um penny, 1602". Ou ainda: “Desde que ele tem 5 ladrões além dele mesmo em sua casa; ou seja, em inglês claro, uma esposa e quatro filhos, $1631{ }^{\prime}{ }^{9}$

Em meio a essas zombarias sem sentido, há, no entanto, registros que parecem refletir uma forte crítica à situação social então vigente. Vários casos significativos poderiam ser aqui discutidos. Um dos itens da cronologia, por exemplo, comenta:

Desde que a Inglaterra foi considerada um lugar muito bom para se viver, e ele [o autor] moraria lá ... se ele pudesse ficar seguro das batalhas de Kenton e de um garoto verdadeiramente canalha de avental branco que trouxe para ela um vil reconhecimento, que espolia tudo. Mas ele não irá fazer questão disso por causa de todas essas mudanças com ela agora ... Porque aqui agora não é nada além de disputa por subornos e um matando o outro por oito pences por dia, além de um pedaço de queijo duro e um pão preto quando ele fica de sentinela... ${ }^{10}$

Ao que tudo indica, neste extenso e confuso item da listagem de ocorrências há embutidas algumas críticas bastante pontuais. E, de fato, numa clara confissão de que seu trabalho não apenas iria apresentar interpretações com base na astrologia, mas também suas opiniões, o autor prometia no almanaque descrever os eventos de acordo com as estrelas, o sol e a lua, e de acordo com o que lhe agradasse.

É bem possível que o "garoto verdadeiramente canalha de avental branco" que despojava as pessoas de tudo o que possuíam, e do qual o nosso autor queria ficar distante, fosse o próprio rei Charles I, cuja coroação havia sido marcante na época dado o incomum uso de um manto branco. Como a identificação de Charles como o rei do manto branco era imediata, a mensagem desse trecho do The Welsh-Mans new Almanack seria facilmente compreendida pelo leitor coetâneo. Ainda a respeito desse trecho citado, pode-se notar que o autor lamenta a guerra e gostaria de poder se afastar daquela situação. As circunstâncias de pobreza e fome dos soldados mal pagos parecem evidentes nas suas observações. Além disso, como transparece pelo seu discurso, a corrupção e o pouco valor à vida eram condições então comuns. Outro trecho da cronologia, que se remete a 1642, indicando-o como o ano em 
que a pilhagem se tornou habitual e os "homens pobres matam-se uns aos outros por oito pences por dia”, parece ser uma clara alusão à Guerra Civil iniciada em outubro daquele ano. ${ }^{11}$

BOOKER VERSUS WHARTON, PROPAGANDA

NA CRONOLOGIA E NO REVIDE À CRONOLOGIA DA GUERRA

Somente vitórias, poucas baixas, superioridade numérica?

Uma das cronologias mais interessantes apresentadas nos almanaques da década de 1640 não é exatamente de fatos relevantes para a história da humanidade em geral, mas sim a já mencionada cronologia da Guerra Civil apresentada por George Wharton em 1644, que compreende eventos até outubro de 1643, quando o almanaque foi escrito.

Essa cronologia destoa completamente não só do que era usual nos almanaques, mas também do que o próprio astrólogo apresentou no seu almanaque para 1642, escrito antes da eclosão da guerra. Naquela ocasião, ele publicou uma habitual listagem de fatos de importância geral para a história da humanidade, que em nada fugia à regra de não se aproximar dos eventos recentes. Terminava sete anos antes de 1642.

Já a cronologia para 1644 dizia respeito exclusivamente aos eventos então recentes e, pode-se notar, é peculiarmente tendenciosa. A guerra parecia correr às mil maravilhas para os partidários do rei Charles I. George Wharton apresentou apenas as vitórias dos realistas, destacando a imensa superioridade das tropas reais frente aos combatentes pelo Parlamento, a quem denominou sugestiva e insistentemente de "Rebeldes", parecendo dar pouca legitimidade aos oponentes.

A respeito dessa denominação, Wharton relatou que, no dia 20 de maio de 1642, a Câmara dos Lordes e a Câmara dos Comuns fizeram uma manobra para evitar que fossem acusados de iniciar uma rebelião contra o rei, e, com isso, tentavam impedir que os chamassem de "Rebeldes". Votaram que "o Rei tinha a intenção de declarar guerra ao Parlamento". ${ }^{2}$

É bem provável que Wharton estivesse fazendo alusão não a 20 de maio, mas sim a 27 de maio, quando o Parlamento declarou que o rei, "convencido por conselheiros maléficos", tinha a intenção de declarar guerra. A partir dessa declaração ficou acertado que nenhuma ordem seria válida a menos que viesse das duas Câmaras. 
O fato de Wharton ter usado a palavra "rebelde" para denominar o grupo com o qual rivalizava, não passou despercebido por John Booker. O astrólogo, partidário das forças parlamentaristas, revidou acusando Wharton e as pessoas reunidas em Oxford, além dos “Sangrentos Rebeldes Irlandeses” de serem os verdadeiros rebeldes: "Vocês são os Rebeldes e traidores de Sua Majestade". ${ }^{13}$

Como oponente, John Booker não tinha motivos para reagir favoravelmente à cronologia do almanaque de George Wharton. Para cada registro de vitória das forças realistas, Wharton invariavelmente mencionou, com detalhes muitas vezes sangrentos e forte ênfase, que o número de mortos e feridos no lado realista foi praticamente ínfimo se comparado ao mesmo tipo de registro no grupo dos defensores da causa do Parlamento. Além disso, no discurso de Wharton, a morte ou captura de oficiais com altas patentes do lado do Parlamento foi sempre destacada como alta e significativa se comparada ao lado Realista. Outro número que ele parecia fazer questão de enfatizar foi o de armas e munições apreendidas.

É interessante notarmos, aliás, que embora o número de soldados comuns mortos pelas forças realistas fosse enorme (segundo a descrição de Wharton), isso não parecia ser tomado pelo autor como crueldade ou ações sangrentas, mesmo diante de um inimigo qualificado como despreparado e inofensivo.

Em compensação, qualquer ação dos oposicionistas contra realistas importantes parecia ser tomada por Wharton como sangrenta ou cruel. Esse é o caso, por exemplo, da morte do Marquês de la Vieuville que, após ter sido feito prisioneiro, teria sido "morto pelos Rebeldes a sangue frio". Acusações de que realizavam "crueldades sangrentas e desumanas" igualmente faziam parte do discurso de John Booker contra os realistas, mas esse, pode-se notar, particularmente se referia à morte de pessoas comuns, penalizadas por uma guerra pela qual não eram responsáveis. ${ }^{14}$

Os discursos desses autores pareciam refletir seriamente suas estratégias propagandistas. Um exemplo típico nesses relatos de Wharton pode ser citado. Num combate em maio de 1643 teria havido centenas de mortos, um número ainda maior de feridos, 1.700 prisioneiros, incluindo 30 comandantes: "havendo não mais de que 46 nas forças do Rei mortos ou feridos, e entre esses nenhum comandante ou Cavalheiro de qualidade". ${ }^{15}$

Pelo discurso do autor, tem-se a impressão de que naquele grupo muitos eram feitos prisioneiros, ao passo que nas tropas realistas isso pouco parecia 

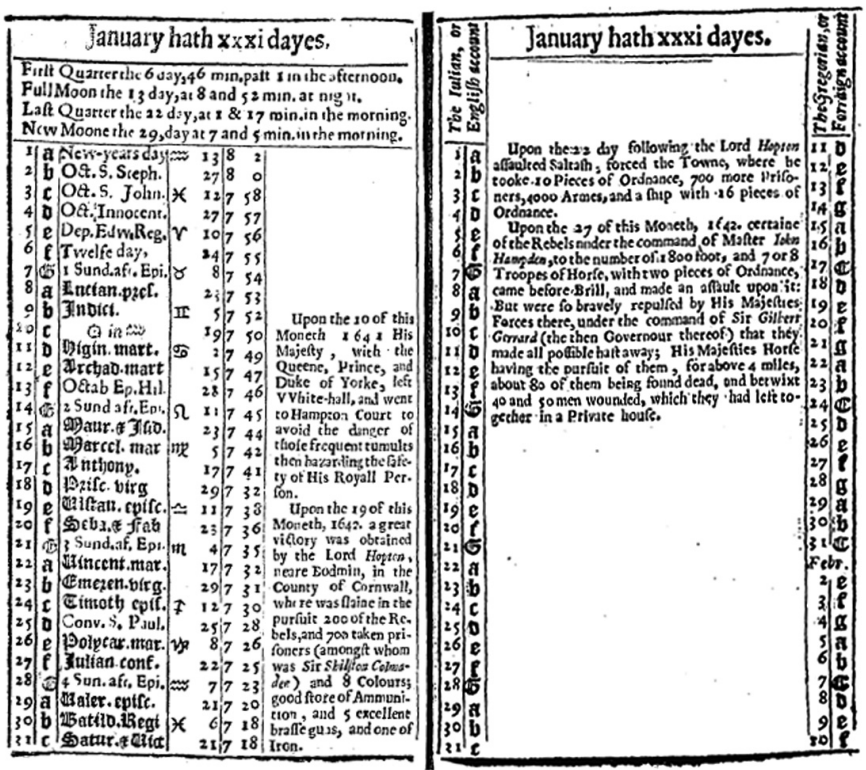

Figura 2 - Folha de calendário com cronologia da

Guerra Civil, extraída do almanaque de Wharton para 1644.

ocorrer. Sabe-se, no entanto, que vários eventos não mencionados poderiam sugerir que a situação não havia sido exatamente assim, e que tropas realistas inteiras foram capturadas em algumas ocasiões. George Wharton, por exemplo, não mencionou que no mês de abril de 1643, Cromwell capturou a tropa realista em Crowland, Lincolnshire.

A linguagem empregada por Wharton foi de plena exaltação às tropas realistas e deboches em relação ao grupo contrário: ${ }^{16}$

os seus Generais foram afugentados e sua tropa completa arruinada.

as forças do Conde de Newcastle ... arruinaram totalmente uma tropa completa de Rebeldes (consistindo em cerca de mais de 3.000 homens)...

foram tão bravamente repelidos pelas forças de Sua Majestade ... que eles fizeram o possível para fugir o mais depressa que puderam...

eles fugiram e tão rápido, que embora tivessem começado a ser perseguidos assim que o Príncipe [Rupert] se apoderou da cidade [Birmingham], ainda assim poucos de seus cavalos foram capturados, e somente cerca de 80 Rebeldes foram mortos, e igual número de Prisioneiros feitos... 
Parlamentaristas incompetentes e covardes

versus realistas competentes e corajosos?

Ineficiência dos "rebeldes" versus eficiência das tropas realistas parece ser a tônica do discurso de Wharton. Os defensores da causa do Parlamento foram delineados como despreparados e covardes. Pareciam sempre fugir desesperadamente do campo de batalha, quando se davam conta da superioridade do inimigo, ou mesmo antes de entrarem no campo de batalha, quando se davam conta de sua culpa. Abandonavam armas, munições e deixavam seus companheiros de luta feridos à sorte dos inimigos. Render-se-iam quando se davam conta de sua impotência para lutar contra as forças realistas. ${ }^{17}$ "Absolutamente arruinados" talvez seja a expressão mais conveniente a ser usada em referência ao modo como a cronologia os descreve.

Alguns pontos, no entanto, merecem ser destacados. Retirar-se dos campos de batalha não foi uma atitude exclusiva das forças favoráveis ao Parlamento. Isso aconteceu mais de uma vez com os realistas. Podemos citar alguns poucos notórios exemplos. Em 4 de abril de 1643, quando sir William Waller se aproximou de Monmouth, as tropas realistas se retiraram para Raglan Castle, permitindo que os defensores da causa do Parlamento ocupassem a cidade. Evento semelhante ocorreu com a tropa liderada pelo conde de Derby em Lancashire, ainda naquele mesmo mês. E, novamente, em setembro de 1643, quando as tropas de Essex chegaram aos arredores de Gloucester, as forças do rei decidiram se retirar. Em outubro daquele ano o fato de repetiu em Newport Pagnell. ${ }^{18}$

$\mathrm{Na}$ cronologia de Wharton, as atitudes de muitos personagens de destaque na Guerra Civil são diretamente contrapostas. Líderes das forças oposicionistas são particularmente mencionados como covardes e incompetentes. Assim Wharton se refere, por exemplo, aos comandantes sir William Brereton e sir John Gell: "Gell e Brereton (dois covardemente Rebeldes)". Em contraposição, comandantes realistas são efusivamente elogiados: "o muito Nobre e valente Conde de Northhampton". ${ }^{19}$

A covardia dos inimigos parece contrastar fortemente com a valentia da família real. A cronologia aponta que a família buscou segurança em Hampton Court, em janeiro de 1642, antes do início efetivo da guerra. O discurso ressalta, no entanto, que tão logo a guerra começou a família real teve alguns de seus membros à frente de tropas. O próprio rei, além de seus filhos, não fugiram ao campo de batalha, servindo de exemplo para outras pessoas, embora tivessem suas próprias vidas ameaçadas. Nas vitórias mencionadas por 
Wharton, nota-se o papel de destaque de outro membro da família real, o príncipe Rupert, no comando das tropas realistas. Rupert, de fato, foi um dos personagens centrais da guerra e atuou intensamente nos combates. Havia, portanto, muitos motivos para que Wharton o elogiasse e os oposicionistas o atacassem: Rupert tornou-se um dos principais alvos do astrólogo defensor da causa do Parlamento William Lilly. ${ }^{20}$

\section{Booker ou Wharton, quem estava certo?}

O caráter francamente tendencioso da cronologia apresentada por Wharton em seu almanaque não passou incólume no século XVII. Booker insinuou que os números apresentados pelo astrólogo real não eram corretos, e que muitas vidas haviam sido desnecessariamente perdidas também do lado realista. Para ele, a intenção de Wharton ao descrever a situação daquela maneira era impedir a reação do público, que se soubesse do real derramamento de sangue iria se revoltar. Chamada por Booker de "infame" ou "nada além de uma coleção de inverdades", a cronologia foi comentada, mas, pode-se notar, de modo não menos tendencioso, pelo astrólogo partidário das forças do Parlamento. Booker parecia insinuar que as verdadeiras vitórias haviam sido somente as dos parlamentaristas. ${ }^{21}$

John Booker acusou Wharton de dizer mentiras: "Leitor, acredite. Nunca houve um número tão grande de Mentiras apresentadas juntas em tão poucas e curtas linhas desde que a palavra Almanaque começou a ser usada". O público que ainda não havia adquirido aquele trabalho foi aconselhado por Booker a, de fato, não o fazer. Assim, evitava o risco de ser persuadido a acreditar nas palavras de Wharton, e tornar-se vítima daquela "doença infecciosa que agora ataca Oxford". 22

Vale a pena discutirmos até que ponto Booker tinha razão ao qualificar a cronologia como mentirosa. Verificando a descrição apresentada por Wharton, nota-se que nem todas as vitórias dos realistas são mencionadas. Ele poderia ter trazido à baila muito mais eventos se assim o quisesse. Citando alguns exemplos, podemos destacar a derrota humilhante de William Waller nas investidas para tomar Basing em novembro de 1643, quando suas tropas chegaram a ser atacadas por mulheres armadas com paus e pedras. Ainda em março daquele ano, os realistas haviam sido bem-sucedidos em Devizes e Malmesbury, por exemplo. E, em maio, ocorreram a ocupação realista em Yorkshire e a vitória de John Byron em Bicester, Oxfordshire. ${ }^{23}$

É bastante significativo, também, que todas as muitas batalhas nas quais 
as tropas do Parlamento venceram foram omitidas por Wharton, assim como muitos outros eventos favoráveis àquele lado do conflito.

Em 7 de janeiro de 1643, por exemplo, um ataque malsucedido dos realistas em Cirencester foi omitido na cronologia. Em compensação, quando de fato as forças realistas conseguiram uma vitória em Cirencester, em 2 de fevereiro, aí Wharton se preocupou em registrar. Em março de 1643 os realistas foram derrotados após intensos combates pelas tropas parlamentaristas sob o comando de sir William Brerenton na "primeira batalha de Middlewich". Em outubro de 1643, os realistas foram derrotados na Batalha de Winceby (também conhecida como Batalha de Horncastle) e tiveram baixas muito superiores às dos inimigos. Na campanha de 1643, à exceção do conde de Newcastle, vários outros comandantes de tropas realistas como os condes de Derby e Carbery, além dos lordes Herbert e Capel sofreram graves derrotas, tiveram tropas inteiras arrasadas ou perderam o controle de áreas já dominadas. ${ }^{24}$

Todos esses eventos foram omitidos por Wharton. Pode-se dizer que a lista de vitórias do Parlamento excluídas, muitas das quais bastante significativas, é bastante extensa e se prolonga por todos os meses da cronologia.

$\mathrm{Na}$ cronologia de Wharton, meses nos quais se pode dizer que a situação se configurou mais favorável ao grupo partidário do Parlamento (como setembro e outubro de 1643) são apresentados de maneira a parecerem mais favoráveis aos realistas. Aliás, todos os meses parecem ter sido não somente favoráveis a eles, como completamente dominados por eles. Isso, no entanto, sabe-se que não correspondeu à realidade.

Por um lado, o mês de julho de 1643 talvez não tenha sido mesmo dos mais favoráveis às forças do Parlamento, pois, de fato, ocorreram as importantes vitórias dos realistas destacadas por Wharton. Por outro, no entanto, houve também vitórias dos parlamentaristas em Gainsborough, ainda que momentâneas, e tentativas frustradas dos realistas em Bradford. ${ }^{25}$

Durante os seis primeiros meses da Guerra Civil várias regiões estavam dominadas pelas forças do Parlamento ou mesmo estavam engajadas a favor dessa porção do conflito. Sendo assim, parece estranho que a descrição de Wharton dessas primeiras ocorrências da guerra correspondesse à realidade. Além disso, o conflito não era fácil para nenhum dos dois lados. Em vários condados como Leicestershire, Nottinghamshire, Cheshire, Lancashire e Yorkshire, nenhuma das forças envolvidas atingiu uma ascendência definitiva durante o inverno de 1642-1643. Quanto aos primeiros meses de 1643, a situação se mostrava indefinida em muitas regiões. Os dois grupos haviam se enfrentado brutalmente a fim de dominar a região de Ribble em direção a 
Mersey, no sul, mas os realistas foram, pouco a pouco, forçados a recuar em direção à costa. Durante um bom período os defensores da causa parlamentarista dominaram importantes regiões do território inglês, e somente com a intervenção do conde de Newcastle, em dezembro de 1642, a situação começaria a mudar. Mesmo assim, nenhuma vitória decisiva nessas regiões ocorreria nos primeiros meses de $1643 .^{26}$

Além disso, se boa parte das descrições apresentadas por Wharton conferem em termos de nomes e locais com o que se conhece a respeito dessas batalhas, é notável o fato de que algumas batalhas nas quais os realistas não poderiam declarar-se vitoriosos tenham sido transformadas pelo autor em grandes triunfos. Wharton descreve, por exemplo, uma vitória altamente favorável ao rei em 20 de setembro de 1643 próxima a Newbury. A disputa, no entanto, conhecida como a "Primeira batalha de Newbury" não teria sido nada favorável aos realistas, que depois de um dia de intenso combate teriam decidido retirar suas tropas, deixando o caminho livre para o conde de Essex, comandante das forças oposicionistas. Nomes e locais da descrição de Wharton conferem, porém o resultado do embate não. ${ }^{27}$

Alguns problemas na cronologia de Wharton foram detectados pelo astrólogo John Booker. Este, no entanto, parece ter respondido a algumas questões também tentando favorecer o grupo do qual fazia parte.

Dirigindo-se aos leitores do almanaque de Wharton, ele argumentou: "Eu poderia contar a ele sobre Alton, Gainsborough, Arundell \&c.". 28 Ostrólogo insinuava que Wharton se absteve, por má fé, de mencionar aquelas batalhas ganhas pelos parlamentaristas.

Pode-se dizer que, de fato, Booker tinha certa razão quando acusava Wharton de ter agido como se as forças realistas fossem as únicas vitoriosas até então na Guerra Civil. Muitas vitórias importantes dos parlamentaristas poderiam ter sido mencionadas caso não se tratasse de uma cronologia tendenciosa e propagandista. Booker estava certo ao lembrar ao leitor o episódio em Alton, quando os realistas foram surpreendidos pelas tropas do Parlamento. A cavalaria realista se dispersou, parte das tropas bateu em retirada e o restante foi capturado. Mas pode-se dizer que Booker ou havia escolhido mal quando decidiu mencionar um daqueles casos, ou também agiu de má fé. De fato, em julho de 1643, Gainsborough chegou a ser tomada pelas forças do Parlamento, mas antes do fim do mês acabou se rendendo aos realistas.

Há ainda batalhas consideradas indecisivas que foram apresentadas por Wharton como grandes vitórias dos realistas. Uma das situações descrita pelo astrólogo nos moldes já mencionados (ênfase e superioridade numérica) 
foi uma suposta grande vitória realista em 23 de outubro de 1642 entre Keynton e Edgehill. A batalha, no entanto, teria sido indecisiva, e ambos os lados do conflito clamaram vitória. ${ }^{29}$

Algumas divergências entre o que teria de fato ocorrido e essa narrativa de Wharton foram insinuadas por John Booker. Para ele a "simples lembrança de Keynton, Edge-hill ou Newbury” fariam o astrólogo realista “cair morto”. ${ }^{30}$

Se considerarmos que, nesse caso, Booker estava insinuando que as tropas do Parlamento haviam vencido essas batalhas, pode-se, então, dizer que ele estava tentando manipular os resultados daqueles conflitos. Mas, se considerarmos que a queixa de Booker dizia respeito ao fato de os realistas não terem sido tão superiores quanto Wharton alegava e, muito pelo contrário, terem passado por situações dramáticas, pode-se dizer que ele tinha razão.

Na batalha de Newbury, cada uma das forças envolvidas no conflito teria perdido cerca de 3.500 homens, mas a porção realista havia perdido alguns de seus partidários mais importantes. As forças realistas decidiram se retirar, embora tivessem conseguido derrotar a cavalaria do Parlamento. O conflito foi, então, considerado um impasse, já que nenhum dos lados podia alegar uma vitória contundente.

Mencionar a batalha de Newbury, portanto, fazia bastante sentido, no que tange a dizer que os realistas não foram tão bem-sucedidos quanto Wharton parecia insinuar. Essa, no entanto, não parecia ser a intenção de Booker. Ao que tudo indica, tanto no caso de Newbury, quanto no de Edgehill e Keynton, cada um tentava tirar partido da situação para o grupo que defendia. Booker insinuava que os parlamentaristas haviam vencido essas batalhas, $\mathrm{e}$ Wharton, por sua vez, que os realistas haviam vencido. Dizer-se vencedor de uma batalha não mudava o resultado do embate já ocorrido, mas influenciava, e muito, os resultados dos embates futuros...

\section{CONSIDERAÇÕES FINAIS}

Os almanaques astrológicos tinham ampla circulação e alcance. Só por isso, já poderiam ser considerados extremamente convidativos no que tange ao seu potencial como veículo de propaganda político-religiosa para quem assim o pretendesse. Além disso, ainda havia muito mais que ressaltasse essa sugestiva potencialidade.

As previsões astrológicas apresentadas nessas publicações eram recebidas com expectativa e credulidade. Para quem assim o desejasse, era possível 
manipular tais previsões de modo a torná-las favoráveis a um grupo ou outro, por exemplo, fazendo-as muito mais específicas do que a astrologia permitia. Isso ocorria no caso das previsões apresentadas nos calendários dos almanaques, que não foram objeto de discussão do presente artigo.

Além disso, como os autores desses almanaques desfrutavam de amplo prestígio, não só o que diziam em termos de prognósticos merecia a atenção do público. E, por isso, partes do almanaque não exatamente relacionadas a previsões astrológicas podiam também ser usadas para enviar mensagens desses autores sobre a realidade que os cercava.

A cronologia, uma seção específica e então comum aos almanaques, foi amplamente usada neste sentido. Era possível, nesse caso, comentar um evento de maneira tal a favorecer ou denegrir a imagem de um grupo ou uma pessoa em particular. Podia-se deturpar ou ocultar dados de modo a reverter situações desfavoráveis, ou ainda enfatizar um ou outro aspecto de determinada situação...

Como vimos aqui, ao apresentarem suas versões dos fatos então ocorridos alguns autores procuraram defender grupos dos quais faziam parte, como foi o caso de John Booker e George Wharton, ou refletiram sobre como aqueles fatos se inseriam no contexto maior da sociedade em que viviam, como foi o caso do Welsh-Mans new Almanack. Nota-se, assim, que os almanaques, e, nesse caso, mais especificamente suas cronologias, representam um material muito rico para compreender como as pessoas daquela época vivenciaram tais acontecimentos e interagiram com aquele contexto.

\section{NOTAS}

${ }^{1}$ Ver CAPP, B. Astrology and the popular press: English Almanacs 1500-1800. London: Faber, 1979. p.20, 45.

${ }^{2}$ BACON, F. The works of Francis Bacon. v.3. Of the dignity and advancement of learning. Ed. J. Spedding. Boston: Taggard and Thompson, 1976. cap. IV, p.353.

${ }^{3}$ Sobre o uso em geral de escritos astrológicos e profecias como propaganda nesse período podemos citar os trabalhos de Harry RUSCHE: "Prophecies and propaganda, 1641 to 1651". The English Historical Review, Oxford: Oxford University Press, v.84, n.333, p.752-770, Oct. 1969; e "Merlini anglici: Astrology and propaganda from 1644 to 1651", idem, v.80, n.315, p.322-333, Apr. 1965.

${ }^{4}$ Para entender a importância desse apoio, a dificuldade para mantê-lo e o efeito negativo das derrotas ver HUTTON, R. The Royalist war effort. In: MORRILL, J. (Ed.). Reactions to the English Civil War 1642-1649. (1.ed. 1982). Hong Kong: Macmillan education, 1986. 
p.51-66; e FLETCHER, A. The coming of war. In: MORRILL, J. (Ed.), 1986, p.29-50. Como comentou Hutton: "houve duas Guerras Civis, a luta formal entre os partidários rivais e a luta entre esses partidários e a população, cujo apoio eles tentaram obter para os seus esforços de guerra" (; HUTTON, 1986, p.52). Todas as traduções apresentadas no presente trabalho são de minha responsabilidade.

${ }^{5}$ Sobre a queda da censura ver HILL, C. The century of revolution, 1603-1714. (1.ed. 1961). London: Abacus, 1974. p.64, 66; e também CAPP, 1979, p.47. A historiadora Norah Carlin afirma que a queda da censura teria possibilitado o tom mais agressivo e o aumento do volume de escritos radicais que defendiam o Parlamento e o direito dos súditos frente à autoridade real (CARLIN, N. The causes of the English civil war. Oxford: Blackwell, 1999. p.150-151).

${ }^{6}$ WHARTON, G., Sir. Naworth, 1641 a new almanack and prognostication for the yeare... London: Company of Stationers, 1641; WHARTON, G., Sir. Naworth, 1642 a new almanack and prognostication for the yeare... London: Company of Stationers, 1642; WHARTON, G., Sir. Naworth. 1644. A new almanack, and prognostication for the yeare...Printed at Oxford: by His Majesties command, by Henry Hall, 1644. A alusão ao rei (grifo meu) na folha de rosto do almanaque de Wharton para 1644 acabaria servindo de mote para deboche. Na folha de rosto do seu Mercurius Coelicus, o astrólogo John Booker se referiu ao almanaque de Wharton da seguinte maneira: "WHARTON, ... 1644. (Dito na página-título ter sido) Impresso em Oxford por ordem de Sua Majestade" (grifo meu; no original: "(Said in the Title Page thereof to be) Printed at Oxford by His Majesties Command)". Booker, assim, parecia colocar em dúvida a autenticidade da informação contida na abertura do almanaque de Wharton, e procurou, no Mercurius Coelicus, desqualificar os escritos do seu oponente (BOOKER, J. Mercurius Coelicus: or a caveat to all people of the Kingdome, that now have, or shall hereafter hapen to reade the counterfeit, and most pernicious Pamphlet whitten under the name of Wharton .. For the yeare ... 1644. London: Company of Stationers, 1644, p.[1]). As páginas dos almanaques geralmente não eram numeradas. Por isso, como a numeração que usamos aqui foi artificialmente introduzida, as referências às páginas serão feitas com o uso de colchetes.

${ }^{7}$ No original: "Our Royall King Charles tooke his journey [March 27] to quiet the Scots". Ver DOVE, J. Dove, an almanack for the Cambridge: Roger Daniel, 1641, p. [47]. Para comentários sobre a grave situação desencadeada pela empreitada mal-sucedida de Charles I ver CARLIN, 1999, cap. 2.

${ }^{8}$ No original: "the damnable powder treason", ver POOLE, J. Poole, 1642 a new almanack and prognostication for the year. London: Company of Stationers, 1642, p. [2]. No original: "the diabolicall attempt of the Powder treason", ver POND, E. Pond's almanack for the yeare London: Company of Stationers, 1643, p. [6]. No original: "Martin Luther first oposed the Pope"; "the massacre of Protestants in France", ver SWALLOW, J. Swallow an almanack for the yeare. London: Company of Stationers, 1641, p. [26]. No original: "Massacre in France" ver WING, V. An almanack and prognostication for the yeare... London: Company of Stationers, 1641, p.[19] e WHITE, J. White 1641 a new almanacke and prognostication for the yeere... London: Company of Stationers, 1641, p.[15]. "The massacre of protestants at 
a marriage in France. Where there was not so much wine drunke, as bloud shed", ver DOVE, 1641, p.[46].

${ }^{9}$ Esses trechos estão localizados na mesma página no original: [ANON]. The Welsh-mans new almanack and prognostication for this present yeare, 1643. Likewise, giving notice to all good peoples to beware of the danger that will befall them; if they take not heed in good time: wherein if there be found any one lye, her will be content to lose all her eredite, and also her other legge and arme, as her did at Kenton battaile. Withall, her doe forbid to have any red letters to be printed in her almanacke, because her do not love the red colour never since her lost so much of her bloud at that time, as her did at Edge-hil. London: [s.n.], 1643, p. [1].

${ }^{10}$ No original: "Since England hath bin counted a very fine place to live in, [a]nd her would live there ... if her could be safe from Kenton battles, and from a very canavish [b] oy in a white apron who brings into her a scurvy reckoning, that spoyles all. Yet her will not for all this change with her now, mark the case ... : For here is nothing now but brible brable, and killing one another for eight pence a day, besides a peice of hard cheese and browne bread when her stands sentinel...]". Ibidem, p.[1]. Nas transcrições do original mantivemos a grafia e pontuação da época, e, no caso do The Welsh-mans new almanack, mantivemos também os erros ortográficos, ao que tudo indica, intencionalmente cometidos pelo autor anônimo.

${ }^{11}$ William Lilly, um dos astrólogos mais importantes da época, também fez alusão ao rei Charles I usando esse artifício na sua interpretação para a "profecia do Rei Branco" (ver LILLY, W. A prophecy of the White King and Dreadfull Dead-man explaned.. London: G. M., 1644). Além disso, críticas ao fato de que as pessoas estavam sendo espoliadas, assim como freqüentes referências à corrupção na época aparecem em trabalhos de Lilly. Ver FERREIRA, J. As influências celestes e a Revolução Científica: a astrologia em debate na Inglaterra do século XVII. Tese (Doutorado em Filosofia) - Programa de estudos Pós-Graduados em Filosofia. São Paulo: Pontifícia Universidade Católica de São Paulo, 2005. cap. 2. O trecho "homens pobres matam-se uns aos outros por oito pences por dia", citado neste parágrafo, é uma tradução livre do original: "poor men kill one another for eight pence a day $1642 "([\mathrm{ANON}], 1643$, p.[1]).

${ }^{12}$ Ver WHARTON, 1644, p.[14]. Em outro trecho do almanaque, Wharton se refere à Câmara dos Lordes e à Câmara dos Comuns, de modo pejorativo, utilizando a expressão "the pretended two Houses" (Ibidem, p.[18]).

${ }^{13}$ BOOKER, 1644, p. [1]. O almanaque de Wharton havia atacado diretamente o astrólogo John Booker e sua publicação para aquele mesmo ano, o que talvez tenha motivado esses comentários tão contundentes.

${ }^{14}$ Os trechos "morto pelos Rebeldes a sangue frio" e "crueldades sangrentas e desumanas" têm, respectivamente, as seguintes localizações nos almanaques de Wharton e Booker: WHARTON, 1644, p.[22] e BOOKER, 1644, p.[2].

${ }^{15}$ Ver WHARTON, 1644, p.[14]. 
${ }^{16}$ As localizações desses trechos no original são respectivamente: WHARTON, 1644, p.[12], [12], [6], [11].

${ }^{17}$ Ver, por exemplo, Ibidem, p.[24].

${ }^{18}$ Para descrições de alguns desses eventos, como a retirada das tropas reais de Gloucester, ver CARLTON, C. Going to the wars: The experience of the British Civil Wars, 1638-1651. London: Routledge, 1992. cap. 6. As retiradas também ocorriam após incursões bem-sucedidas, pois, devido à intensidade dos combates, mesmo os vencedores às vezes se viam em situação precária.

${ }^{19}$ Os trechos citados nesse parágrafo encontram-se na mesma página no original do almanaque: WHARTON, 1644, p.[9]. É pouco provável que os comandantes das tropas realistas fossem tão mais competentes do que os seus adversários, como Wharton procurava destacar. Ao iniciar a campanha de 1643, o rei havia delegado o comando de tropas a pessoas inexperientes, escolhidas em função do status social e prestígio local a fim de conseguir harmonia entre as tropas e as comunidades locais. A medida se mostraria inadequada, pois boa parte das tropas sofreu tão graves derrotas, que o rei se viu obrigado a reverter a estratégia e delegá-las a homens de destacadas habilidades militares como o príncipe Rupert (ver HUTTON, 1986, p.55-56).

${ }^{20}$ A respeito da atitude do rei no conflito, Wharton apontava: "Cuja destemida coragem Real deu ânimo a todos os homens” (WHARTON, 1644, p.[24]). Para referências de Wharton a Rupert ver Ibidem, p.[7], [15], [18]; e para os comentários do astrólogo sobre a ida da família real para Hampton Court ver Ibidem, p.[5]. A transferência da família real para Hampton Court é objeto de estudo de Conrad Russell no cap. 12 de sua obra The Fall of the British monarchies, 1637-1642. Oxford: Oxford University Press. Para comentários sobre os ataques de William Lilly a Rupert ver FERREIRA, 2005, cap. 2, seção 3 e GENEVA, A. England's propheticall Merline decoded: a study of the symbolic art of astrology in Seventeenth Century England. Tese (Doutorado em História) - State University of New York. New York: Stony Brook, 1988. p.350-359, 399-401.

${ }^{21}$ No original: "All that Infamous Chronology is nothing else but a Collection of Untruths..." (Ibidem, p.[1]; os itálicos estão no original). "Vitórias são nossas, as Ficções de vocês" dizia Booker (Ibidem, p.[1]). No original: "Victories are ours, Fictions yours". Para Booker, se os realistas alguma vez haviam vencido isso ocorrera por causa de alguma "traição" (No original "Treachery"; Ibidem, p.[2]).

${ }^{22}$ Os trechos citados neste parágrafo foram extraídos, respectivamente, das seguintes páginas do almanaque de Booker: Ibidem, p.[2], [1].

${ }^{23}$ Para o episódio em Basing ver CARLTON, 1992, p.178. Para outras vitórias realistas ver, também, FLETCHER, 1986, p.32.

${ }^{24}$ WHARTON, 1644, p. [7]. Para detalhes sobre esses episódios ver CARLTON, 1992, p.174175, 235; FLETCHER, 1986, p.32 e HUTTON, 1986, p.56.

${ }^{25}$ Wharton citou as batalhas de Lansdown e Roundway Down (ver WHARTON, 1644, p.[17-18]). 
${ }^{26}$ Ver FLETCHER, 1986, p.32-35 para descrições de vários casos em que os territórios não estavam dominados e as forças em guerra se equilibravam.

${ }^{27}$ Para a descrição de Wharton a respeito de uma pretensa vitória realista nesta batalha ver WHARTON, 1644, p.[22]. Talvez ambos os lados do conflito tenham ficado satisfeitos com a atuação de seus soldados nessa batalha. Como reconheceu Bulstrode Whitelocke, defensor da causa do Parlamento: "both sides performed then with good manhood and animosity” (Apud CARLTON, 1992, p.5). Para detalhes sobre a batalha de Newbury ver GUIZOT, F. Histoire de la révolucion d'Anglaterre. Paris: Robert Laffont, 1997, p.237-238 e CARLTON, 1992, p.119.

${ }^{28}$ Ver BOOKER, 1644, p.[1].

${ }^{29}$ Wharton descreveu efusivamente a suposta vitória realista (ver WHARTON, 1644, p. [23]). $\mathrm{Na}$ época, alguns panfletos descreveram essa batalha como uma grande derrota, ao passo que outros a descreveram como um grande triunfo das tropas do Parlamento. Segundo alguns desses, aliás, o embate teria culminado com a captura do príncipe Rupert (ver CARLTON, 1992, p.231). Para comentários sobre os episódios em Edgehill ver CARLTON, 1992, p.114-118 e GUIZOT, 1997, p.207-210. As alegações de Wharton de superioridade numérica não seriam pertinentes. Ambos os lados perderam cerca de 3 mil combatentes no conflito e tiveram outros 3 mil feridos.

${ }^{30}$ BOOKER, 1644, p.[1].

\section{AGRADECIMENTO}

A autora agradece à Fundação de Amparo à Pesquisa do Estado de São Paulo (Fapesp) o apoio a esta pesquisa.

Artigo recebido em fevereiro de 2007. Aprovado em dezembro de 2007. 